\title{
Interfaces participativas na pesquisa metodológica para as investigações em enfermagem
}

\author{
Participatory interfaces in methodological research for nursing investigations \\ Interfaces participativos en la investigación metodológica para las investigaciones en enfermería
}

\section{Elizabeth Teixeira ${ }^{1}$}

A Pesquisa Metodológica emerge nas publicações em enfermagem em 2006 e apresenta significativo aumento a partir de 2015 . $^{1}$

Uma referência da área de ciências sociais define-a como uma modalidade de pesquisa de métodos e procedimentos adotados como científicos, fazendo parte de seu escopo o estudo dos paradigmas, as crises da ciência, os métodos e as técnicas. ${ }^{2}$ A pesquisa metodológica, nesta referência, compõe um quadrilátero, junto com a pesquisa teórica, pesquisa empírica e pesquisa prática. ${ }^{2}$ A referência mais citada na área da enfermagem indica-a como a investigação dos métodos, envolvendo a produção-construção, a validação e a avaliação destes, com foco no desenvolvimento de novos instrumentos-produtos. ${ }^{3}$

A sua utilização na enfermagem tem sido encontrada em quatro modalidades de estudos: desenvolvimento de instrumentos de medida; desenvolvimento de tecnologias assistenciais, gerenciais e/ou educacionais (também classificadas como materiais ou imateriais, de produto ou de processo); tradução e adaptação transcultural de instrumentos produzidos em outros países; validação de diagnósticos, resultados e intervenções de enfermagem.

Há múltiplas denominações em curso na área de enfermagem: pesquisa metodológica, estudo metodológico, estudo de desenvolvimento metodológico, estudo de validação, dentre outros.

$\mathrm{Na}$ descrição dos meios e métodos de pesquisa, os autores têm indicado a sua utilização por meio de etapas ou fases. Não há uma quantidade precisa de etapas ou fases; tal indicação vai depender dos objetivos. Há estudos com cinco fases: diagnóstico situacional, revisões de literatura; construção do instrumentotecnologia; validação aparente e de conteúdo; teste piloto. ${ }^{4}$ Também há com 3 etapas: construção da tecnologia educativa; validação do material por juízes; legitimação do mesmo material pelo público-alvo. ${ }^{5}$

Outro aspecto metodológico que se evidencia nos estudos é a complementariedade de abordagens, quantitativas e qualitativas, o que indica a possibilidade de ser realizada por meio de pesquisa

\footnotetext{
${ }^{1}$ Enfermeira. Doutora. Universidade do Estado do Amazonas. Centro Universitário Luterano de Manaus. Manaus, Amazonas, Brasil. etfelipe@hotmail.com. ORCID: http://orcid.org/0000-0002-5401-8105
} 
Interfaces participativas na pesquisa metodológica para as investigações em enfermagem (2)

de métodos mistos, no sentido de combinar elementos de ambas abordagens para o propósito de ampliar e aprofundar o entendimento e a corroboração. ${ }^{6}$

Cabe ressaltar ainda na perspectiva metodológica, que os estudos de validação adotam múltiplos processos e recursos estatísticos, ${ }^{1}$ com vistas a identificar índices de concordância (Índice de Validade de Conteúdo-IVC) ou consenso (Técnica Delphi), incluindo não só juízes-especialistas da área da saúde como de outras áreas, que avaliam aspectos distintos. No que tange aos estudos de aplicação, tem-se utilizado desenhos experimentais e quase-experimentais, e a utilização de pré-teste e pós-teste como técnica para a verificação da eficácia do material validado.

Há, no entanto, poucos estudos na enfermagem brasileira em que há interface entre a pesquisa metodológica e a pesquisa ação participativa em saúde (PAPS), apesar do grande interesse internacional na aplicação desta metodologia, que suscita a co-criação de conhecimento com os sujeitos-alvo da pesquisa, possibilitando também gerar dados para a resolução de problemas de saúde e para a mudança social. ${ }^{7}$

É também emergente no Brasil estudos metodológicos que utilizam como modelo conceitual a Tradução do Conhecimento (Knowledge Translation). Neste modelo, no momento em que se produzem ferramentas/produtos do conhecimento, estes são produzidos junto ao público-alvo, que tem participação ativa no processo. ${ }^{8}$ Nesse sentido, o objetivo deste texto é apresentar três "densidades" de participação que poderão potencializar interfaces participativas na pesquisa metodológica e ampliar as possibilidades desta modalidade na pesquisa em enfermagem no Brasil.

A primeira "densidade", de baixa intensidade, é possibilitada após-a-criação do instrumentotecnologia, em que o público-alvo é partícipe da etapa de validação semântica ou de aparência. Nessa etapa, o público-alvo entra em contato direto com o instrumento-tecnologia já produzido e validado por juízes-especialistas, e pode manifestar sua opinião sobre aspectos como objetivos, organização, estilo da escrita, aparência e motivação, sem interferência no conteúdo.

A segunda "densidade", de média intensidade, é possibilitada antes-da-criação do instrumentotecnologia. Nessa etapa, o público-alvo participa de uma fase diagnóstica-exploratória, em que o pesquisador visa identificar o seu saber-fazer cotidiano no que tange ao conteúdo do instrumentotecnologia, que será então criado tendo como base tanto os temas geradores emergentes da respectiva fase como as evidências da literatura emergentes de revisões.

A terceira "densidade", de alta intensidade, é viabilizada com a co-criação do instrumentotecnologia. Nessa etapa, o público-alvo não só manifesta seu saber-fazer cotidiano como participa da criação. O desenvolvimento participativo de instrumentos-tecnologias, na nossa experiência de pesquisa, se deu por meio de grupos focais de desenvolvimento, em que além da interação-diálogo guiado por um roteiro, pesquisador e público-alvo, juntos, em vários encontros, organizaram, elaboraram, ilustraram, enumeraram, enfim, teceram juntos tanto o conteúdo como a aparência. 
O uso dessas diferentes "densidades" de participação podem ser consideradas novas possibilidades para investigadores "metodológicos" interessados em fazer incursões nas abordagens participativas.

Além disso, consideramos que as "densidades" de média e alta intensidade oportunizam o empowerment enquanto aumento de poder pessoal e coletivo de indivíduos e grupos sociais. ${ }^{9}$ Portanto, reforça-se o potencial da interface participativa e as múltiplas possibilidades de aplicação da Pesquisa Metodológica na pesquisa em enfermagem.

\section{Referências}

1. Mantovani MF, Sarquis LMM, Kalinke LP, Kuznier TP, Pizzolato AC, Mattei AT. Pesquisa metodológica: da teoria à prática. In: Lacerda MR, Ribeiro RP, Costenaro RGS, organizadoras. Metodologias da pesquisa para a enfermagem e saúde: da teoria à prática Volume II. Porto Alegre; Editora Moriá; 2018. p. 151-76.

2. Demo P. Pesquisa e construção do conhecimento. Rio de Janeiro; Editora Tempo Brasileiro; 1994.

3. Polit DF, Beck CT. Fundamentos de pesquisa em enfermagem. 7nd ed. Porto Alegre; Editora Artmed; 2011.

4. Benevides JL, Coutinho JfV, Pascoal Lc, Joventino ES, Martins Mc, Gubert FA, et al. Development and validation of educational technology for venous ulcer care. Rev Esc Enferm USP. [Internet] 2016 [acesso em 2019 Jan 9]; 50(2):306-312. Disponível em: http://www.scielo.br/pdf/reeusp/v50n2/00806234-reeusp-50-02-0309.pdf doi: 10.1590/S0080-623420160000200018.

5. Oliveira SC, Lopes MVO, Fernandes AFC. Construção e validação de cartilha educativa para alimentação saudável durante a gravidez. Rev. Latino-Am. Enfermagem. [Internet] 2014 [acesso em 2019 Jan 9]; 22(4):611-20. Disponível em: http://www.scielo.br/pdf/rlae/v22n4/pt_0104-1169-rlae-2204-00611.pdf doi: 10.1590/0104-1169.3313.2459.

6. Creswell JW, Clark VLP. Pesquisa de métodos mistos. 2nd ed. Porto Alegre: Editora Penso; 2013.

7. Wright MT, Brito I, Cook T, Harris J, Kleba ME, Madsen W, et al. O que é a pesquisa-ação participativa em saúde: ICPHR Position Paper 1. 2018 [acesso em 2019 Jan 9]; Disponível em: http://www.icphr.org/uploads/2/0/3/9/20399575/icphr_position_paper_1_pt.pdf

8. Cabral IE, Bubabué RM, Oliveira JD, Paula CC, Cherubin D. Knowledge Translation: um caminho metodológico para converter resultados de pesquisa em prática de saúde e enfermagem. In: Teixeira E, organizadora. Desenvolvimento de tecnologias cuidativo-educacionais. Porto Alegre; Editora Moriá; 2017.

9. Carvalho PAL, Sena ELS, Souza VS. O empowerment como estratégia de cuidado à família de pessoas em sofrimento mental. Cadernos Brasileiros de Saúde Mental. [Internet] 2014 [acesso em 2019 Jan 9]; 6(13): 87-103. Disponível em: http://incubadora.periodicos.ufsc.br/index.php/cbsm/article/view/1761.

\section{Como citar este artigo}

Teixeira E. Interfaces participativas na pesquisa metodológica para as investigações em enfermagem. Rev. Enferm. UFSM. 2019 [Acesso em: Ano Mês Dia];9, e1:1-3. DOI:https://doi.org/10.5902/2179769236334 